\title{
Mobile Assisted Language Learning in Saudi EFL Classrooms: Effectiveness, Perception, and Attitude
}

\author{
Raghad Y. Alkhudair \\ Department of English Language and Translation, College of Arabic Language and Social Studies, Qassim University, \\ Qassim, Saudi Arabia
}

\begin{abstract}
The utilization of mobiles in EFL classrooms offers valuable opportunities for creating an effective learning environment. To determine the role of such a technology, the present study investigates the effectiveness of using m- learning or MALL in EFL classrooms, and how the use of such an apparatus correlates with the learners' academic achievements. It also examines the perceptions and attitudes of EFL students towards applying MALL in the classroom as an educational tool. A hybrid design containing both quantitative and qualitative questions was employed for the purpose of collecting the data. A total number of 126 students from different Saudi universities have been surveyed. Then, the data were analyzed and tested using Pearson test of relationship as well as descriptive statistics. The findings exhibited a positive correlation between the hours of using mobiles for learning purposes and the students' academic performance. Furthermore, the participants perceived m-learning as a beneficial and assistant tool, and expressed positive attitudes concerning its implementation in the classroom.
\end{abstract}

Index Terms-English learning, MALL, ESL, EFL, CALL, English for specific purposes

\section{INTRODUCTION}

In the world that emerging technology devices are rapidly growing, a variety of technological solutions have been incorporated into instructive settings. The integration of such technologies undergoes a gradual process as educators need to comprehend the nature of the technological apparatuses and how they effectively enhance the learning process (Kukulska-Hulme \& Shield, 2008). In this regard, English for specific purposes instruction has been positively influenced by the advantages of the technological aids and solutions. One of the early-established language teaching and learning technology was Computer-assisted language learning (CALL) which had a great impact on the pedagogical process as it supplies educators with the most recent and pertinent information (Moore \& Calvert, 2000). CALL stands out in terms of providing the learners more independence from classrooms and allows them to progress and work at their own speeds (Rost, 2002). Such a technology influences the cultural practices and offers new and alluring learning contexts (Pachler et al., 2010).

However, regardless of CALL's prosperity, a new trend of technology has emerged in the last few years and attracted global attention. Mobile technology or Mobile learning (M-learning) or Mobile Assisted Language Learning (MALL) is a new area of practice and research in the field of foreign and second language instruction (Godwin-Jones, 2017). Kukulska-Hulme and Traxler (2005) defined MALL as a "learning method mediated by the assistance of small portable devices that can be adapted to the learner's immediate context" (p. 124). Geddes (2004), in the same vein, considered MALL as a learning method which posits no restrictions on time or place, thus, provides "a myriad of opportunities to support learning and performance both inside and outside the classroom" (Martin \& Ertzberger, 2013, p. 26). O'Malley et al., (2005) described MALL from the stance of the learner as " any sort of learning that happens when the learner is not at a fixed, predetermined location, or learning that happens when the learner takes advantage of learning opportunities offered by mobile technologies" (p. 15). Therefore, to attain deep understanding of MALL, the given study aimed at determining the effectiveness of MALL in Saudi EFL classrooms as well as exploring its nature from EFL learners' perspective.

\section{LITERATURE REVIEW}

\section{A. MALL: Characteristics, Advantages, and Disadvantages}

Regardless of the hurdles to M-learning such as the financial cost, technical issues and considerations, and accessibility, the available evidence assumes that M-learning bears considerable advantages concerning education (ElHussein \& Cronje, 2010). Pachler, Bachmair, and Cook (2010) clearly indicated the key features of mobile devices which make them attractive from an educational standpoint, that is, "increasing portability, functional, multimedia convergence, ubiquity, personal ownership, social interactivity, context sensitivity, location awareness, connectivity, and personalization" (p. 12). Likeways, Huang and Lin (2012) and Zaki and Yunus (2015) have addressed different 
characteristics of mobiles in EFL classrooms, namely, mobility, ubiquity, flexibility, interactivity, small equipment size, accessibility, and privacy. Lee and Chan (2007) attributed the observed prosperity and success of M-learning to many factors such as, among others, providing practices for learners through experiential learning, encouraging the communication process between teachers and students, offering authentic and reliable materials, and focusing on the individual necessities.

As mentioned earlier, the mediated learning by mobiles exhibits several disadvantages such as technical and ethical issues. Further disadvantages have also been highlighted by Miangah and Nizarat (2012). They stated that the small screen size, high cost, and untrusted data storage system are obstacles to adopt MALL as an educational approach. Additionally, Viberg and Gronlund (2013) considered the dependence on the Internet as a problematic characteristic for some EFL learners. Since the internet might suffer from unstableness connection, some students could end up with less knowledge and understanding of the subject.

\section{B. The Effectiveness of MALL in Educational Contexts}

The implementation of MALL to support language practice and enhance language learning has shown a wobbling status in the reviewed literature (Pachler et al., 2010; Pollara \& Kee Broussard, 2011; Şad \& Göktaş, 2013; Rezaei et al., 2014). Ozer and Kilıç (2018) declared that in order for MALL to be a beneficial tool in the classroom, the scope of the contextual features of educational institutions must be taken into consideration. In their study of vocabulary acquisition via MALL, Rezaei et al., (2014) concluded that M-Learning can be credited with promoting effective vocabulary learning, thus, helps the students to achieve high grades. Pollara and Kee Broussard (2011) analyzed the outcomes of M-learning tasks and asserted that m-learning has "instructional value and the potential to positively affect learning in a variety of contexts" (p. 23). Similarly, Loewen et al., (2019) investigated the significance of M-learning by observing the progress of nine participants who acquire and practice the targeted language by using Doulingo application. The findings showed a great improvement in the students' language proficiency and skills as well as high motivation and engagement to the lessons. Azar and Nasiri (2014) undertook an experimental study to elicit and identify the effectiveness of MALL enforcement in the EFL classroom. The result suggested that MALL demonstrates a strong efficiency in the classroom as the students in the experimental group were highly encouraged and outperformed the control group. The increase in learners' motivation is a supported result by many scholars including Petkov and Rogers (2011), Huang, Lin, and Cheng (2010). However, some drawbacks of using MALL in English classes have also been admitted in a number of studies. For example, Sung, Chang, and Liu (2016) found that utilizing mobile devices in educational contexts had a moderate impact on the learners' achievement. A further study conducted by Kuznekoff and Titsworth (2013) which was designed to discover the influence of using mobile phones during lectures on the students' achievement. The study revealed interesting outcomes, that is, the students who abandoned the use of mobile phones during the lecture wrote down $62 \%$ detailed notes more than the group who utilized mobiles. In this regard, Kibona and Mgaya, (2015) contended that mobiles or smartphone could bring negative results or progression on students' performance academically.

\section{MALL: Perceptions and Attitudes}

The perceptions and attitudes towards MALL in EFL classrooms have also been a matter of investigation. A number of empirical studies have emerged to determine teachers' and students' perspectives and attitudes of MALL (e.g., Saran et al., 2009; Hsu, 2013; Oz, 2015; Saidouni \& Bahloul, 2016). Wu et al., (2012) performed a meta-analysis to examine MALL-related issues. They asserted that the majority of MALL studies revealed positive attitudes with regard to mobility (Şad \& Göktaş, 2013), effortlessness of gathering and obtaining the data for different academic purposes (Sharples \& Vavoula, 2009), the ability to learn outside the classroom realm (Saran et al., 2009), and at any place and time (Sabzian \&Gilakjani, 2013). Hsu (2013) focused on examining MALL from cross-national EFL learners' perspective. Given that, the conclusion of Hsu's (2013) study was a hallmark in MALL's literature. That is, although the participants were selected from different nationalities, educational backgrounds, and experiences, all of them revealed positive attitudes and agreement concerning the application of MALL in the classroom. Other studies (Oz, 2015; Saidouni \& Bahloul, 2016) adopted different perception's scales such as Uzunboylu and Ozdamlis' (2011) scale to examine the perception of MALL among EFL teachers and learners. The findings suggested a high level of agreement to approve MALL as a pedagogical tool since it allows the educators to reach various educational resources.

As for Dashtestani (2013), who explored the teachers' stances of MALL application in classroom, the result was not quite positive. Most of the teachers did not demonstrate MALL in EFL classroom and expressed some contentions to use and develop MALL activities. Also, the study of Abidin et al., (2016) which concentrated on the ethical considerations of using mobiles in the classroom exposed that most of teachers conceived mobiles as to stimulate distraction and cheating in the classroom; a position supported by Froese's (2012) and Metruk (2020).

Therefore, in light of the above, we can consider M-Learning as a double-edged sword. It serves as a pedagogical tool if it is used appropriately to improve the students' knowledge of language and clarify unfamiliar or difficult information (Huang, Lin and Cheng, 2010), or as a source of distraction (Froese et at., 2012), and cheating (Metruk, 2020). Accordingly, and based on the rationale given in the preceding sections, this study will identify the role of $M$ learning in Saudi academic sittings by answering the following questions: 
1. Is there a statistically significant relationship between the hours of using mobiles and educational applications in learning English and EFL learners' grade point average (GPA)?.

2. What are the EFL learners' perceptions and attitudes towards the use of MALL in classroom?

For the purpose of hypothesis testing, the following hypotheses were formulated:

$\mathbf{H}^{\mathbf{0}}$ : There is no a statistically significant relationship between the hours of using mobiles and educational applications in learning English and the EFL learners' grade point average (GPA).

H: There is a statistically significant relationship between the hours of using mobiles and educational applications in learning English and the EFL learners' grade point average (GPA).

\section{Methodology}

The present study adopts quantitative and qualitative data collection procedures. Below is a brief outline of the methodological framework within which the present study is conducted.

\section{A. Participants}

The participants of the present case study consisted of 126 students who majored in linguistics and translation department of English language at Qassim university $(\mathrm{N}=56)$, King Abdul Aziz university ( $\mathrm{N}=48)$, and Imam Mohamad bin Saud university $(\mathrm{N}=22)$. The students were chosen in a random manner in order to reach a wide number of learners from various classes and proficiency levels, thus, achieving better and deep insights of the matter under investigation. A mix of males and females whose age ranged from 18 to 27 years old have participated in the current study. In order to avoid any confounding variable, the number of males and females was controlled. The following tables (1-2) show the descriptive statistics of the subjects' sociodemographic information.

TABLE 1

DESCRIPTIVE STATISTICS FOR AGE (IN YEARS).

\begin{tabular}{|c|c|}
\multicolumn{2}{|c|}{ DESCRIPTIVE STATISTICS FOR AGE (IN YEARS). } \\
\hline Age & Statistics \\
\hline & \\
Max. Age & 27 \\
\hline Min. Age & 18 \\
\hline Mean & 21 \\
\hline Total & 126 \\
\hline
\end{tabular}

TABLE 2

DESCRIPTIVE STATISTICS FOR GENDER

\begin{tabular}{|c|c|c|}
\hline \multicolumn{2}{|c|}{ DESCRIPTIVE STATISTICS FOR GENDER } \\
\hline Gender & Frequency & Percent \\
\hline Male & 63 & $50 \%$ \\
\hline Female & 63 & $50 \%$ \\
\hline Total & 126 & 100 \\
\hline
\end{tabular}

\section{B. Data Collection Instrument}

For the aims of this research, it has been decided to select an adopted scale and to add open-ended questions. The questionnaire consists of three parts. The first is concerned with the participants' sociodemographic information in terms of name, age, and gender. The second part included three main questions. One was a closed-ended question of a multiple-choices kind which investigates how many hours each participant uses the mobiles and educational application to study English. The students were asked to be as accurate as possible in selecting one choice out of ten (from one hour to ten hours per a week). The two others were of an open-ended type which requested the participant to mention the name of the university and their own grade point average (GPA) on a 5.0 scale. According to the Saudi grading system, Saudi universities may either have a GPA scale of 4.0 or 5.0. Therefore, the students were asked to specify their GPA type (4.0 or 5.0), then, the students' GPAs with a scale of 4.0 were transformed to 5.0.

The third part of the questionnaire included Mobile Learning Perception Scale (MLPS) adapted from Uzunboylu and Özdamlı (2011) and an open-ended question. The scale includes 26 statements to statistically measure the learners' perceptions of m-learning concerning three indicators (see table 3): Aim-Mobile Technologies Fit (A-MTF), Appropriateness of Branch (AB), and Forms of M-learning Application and Tools' Sufficient Adequacy of Communication (FMA and TSAC). The participants rated the statements on a 5-point Likert scale (ranging from 1. strongly agree to 5. strongly disagree). The Internal consistency of the scale was verified by the Cronbach's alpha value. The value of Cronbach's alpha for the whole scale developed by Uzunboylu and Özdamlı (2011) was .97 whereas in this study the reliability coefficient of the scale was .87 (see table 3). Field (2009) declares that if Cronbach's alpha value of the scale was higher than .70 , the instrument is considered reliable and had good psychometric properties (Field, 2009). 
TABLE 3

VARIABLES AND RELIABILITY

\begin{tabular}{|c|c|}
\hline Dimension & Number of Items \\
\hline A-MTF_-Aim-Mobile Technologies Fit & 8 \\
\hline $\mathrm{AB}$-Appropriateness of Branch & 9 \\
\hline $\begin{array}{l}\text { FMA and TSAC-Forms of M-learning Application } \\
\text { and Tools' Sufficient Adequacy of Communication }\end{array}$ & 9 \\
\hline Total & Cronbach's Alpha $=.87$ \\
\hline
\end{tabular}

The open-ended question was added to explore the advantages and disadvantages of using MALL in the classroom from the learners' point of view. Then, the questionnaire was circulated to the participants through e-mail and Telegram application. Robson (2011) recommended using electronic questionnaires since they assess the researcher to reach more audience in a short period of time and low cost.

\section{Data Analysis}

The data was statistically analyzed via Statistical Package for Social Sciences (SPSS). To assess the relationship between the academic performance and hours of using mobiles in learning English, the researcher used Pearson Correlation test of relationship. Also, descriptive analysis was performed to calculate the mean and the standard deviation of MLP scale's variables. To control any bias towards a certain type of gender, a number of 11 cases were removed from the dataset. In addition, the researcher has excluded the unrelated data (outliers) from each variable of the data. These procedures resulted in 19 cases being removed and yielded a final analysis sample of 126 students.

\section{FINDINGS}

As indicated earlier, this study was set to address two main research questions. The first aims at exploring the relationship between the number of hours in using mobiles and mobiles' applications for studying and preparing for the class and the EFL students' grade point average (GPA). The second research question seeks to elicit and investigate the perception and attitude of EFL learners towards the use of mobiles (or MALL) as a pedagogical aid. To answer the research questions, a hybrid questionnaire was demonstrated to a random sample of Saudi EFL learners who enrolled in English language departments at some Saudi universities. The questionnaire consists of open-ended questions and an adopted questionnaire (MLP Scale) that contained 26 Likert Scale based statements. Therefore, this section presents the results of that statistical analysis of the given questionnaire.

\section{A. Quantitative Analysis}

\section{Pearson Correlation}

In terms of testing the null hypothesis that there is no relationship between students' hours of using mobiles and educational applications in learning English and their academic performance or GPA, a bootstrapped Pearson Correlation test was utilized. From this data set, the assumptions of Pearson Correlation were examined, and a preliminary analysis was performed to assess the normality and linearity of the data. However, since some assumptions are hardly to be satisfied, Larson (2015) recommended using bootstrapping or robust methods as a suitable amend.

TABLE 4

PEARSON CORRELATION

\begin{tabular}{|c|c|c|c|c|c|}
\hline & & & & GPA & $\begin{array}{l}\text { Hours of Using Mobiles In Learning } \\
\text { English }\end{array}$ \\
\hline \multirow[t]{6}{*}{ GPA } & \multicolumn{3}{|c|}{ Correlation Coefficient } & 1.000 & $.801^{* *}$ \\
\hline & \multicolumn{3}{|c|}{ Sig. (2-tailed) } & . & .000 \\
\hline & \multicolumn{3}{|l|}{$\underline{N}$} & 126 & 126 \\
\hline & \multirow[t]{3}{*}{ Bootstrap $^{b}$} & Bias & & .000 & $-.001-$ \\
\hline & & \multirow{2}{*}{$\begin{array}{l}95 \% \\
\text { Interval }\end{array}$} & ConfidenceLower & 1.000 & .778 \\
\hline & & & Upper & 1.000 & .908 \\
\hline
\end{tabular}

Table (4) above demonstrates that a total of 126 EFL students were surveyed about the hours they spend in using mobiles to learn English and their GPA. Based on the given analytical procedure, there was a strong positive significant relationship between students' hours of using mobiles and educational applications in learning English and their GPA with a criterion of significance $95 \%$ CI $[.778, .908]$ and coefficient $r=.801$. The CI is seen to be narrow since it represents nearly one-point difference between the two values. The two asterisks of the $r_{\mathrm{s}}$ value indicate the strength of the relationship which is considered as a highly strong relationship as the $r$ value reveals, therefore, we reject the null hypothesis.

2. Descriptive Statistics of EFL Learners' Perceptions and Attitudes Towards MALL 
TABLE 5

\begin{tabular}{|c|c|c|}
\hline Items and Item Descriptions & Mean & St. deviation \\
\hline 1. M-learning tools remove the limitation of time and space. & 4.07 & .99 \\
\hline 2. Mobile applications create effective learning-teaching environments. & 3.85 & 1.0 \\
\hline \multicolumn{3}{|c|}{$\begin{array}{l}\text { 3.Applications such as Skype and Twitter provide opportunities to use authentic language without the limitation of time and space. } \\
3.09\end{array}$} \\
\hline $\begin{array}{l}\text { 4. An effective learning environment could be provided by sending lec } \\
\text { such as e-mail, MMS or SMS. }\end{array}$ & $\begin{array}{l}\text { notes, wo } \\
3.67\end{array}$ & $\begin{array}{l}\text { r pronunciations via M-learning tools } \\
1.14\end{array}$ \\
\hline \multicolumn{3}{|c|}{ 5. M-learning is an effective method in exact transmission of knowledge in learning activities. } \\
\hline 6. Utilization of m-learning technologies increases my motivation. & 4.01 & .91 \\
\hline 7. M-learning systems increase the quality of lessons. & 3.90 & .987 \\
\hline \multicolumn{3}{|c|}{ 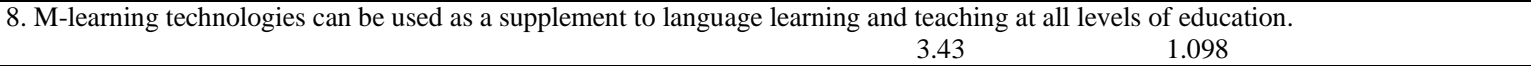 } \\
\hline Weighted Mean & 3.64 & \\
\hline
\end{tabular}

The dimension A-MTF-Aim-Mobile Technologies Fit seeks to assess the appropriateness of the traditional and mlearning goals (Zaminga et al., 2017). As shown in table (5), most of the learners have positively evaluated the items since the average score $(M=3.64)$ for the whole dimension was within the upper third of the normative distribution (34). Furthermore, the results for this factor show that the highest mean score $(\mathrm{M}=4.07, \mathrm{SD}=.99)$ was achieved by the first item (M-learning tools remove the limitation of time and space) while the fourth statement (Applications such as Skype and Twitter provide opportunities to use authentic language without the limitation of time and space) obtained the lowest mean score $(\mathrm{M}=3.09, \mathrm{SD}=1.03)$.

TABLE 6

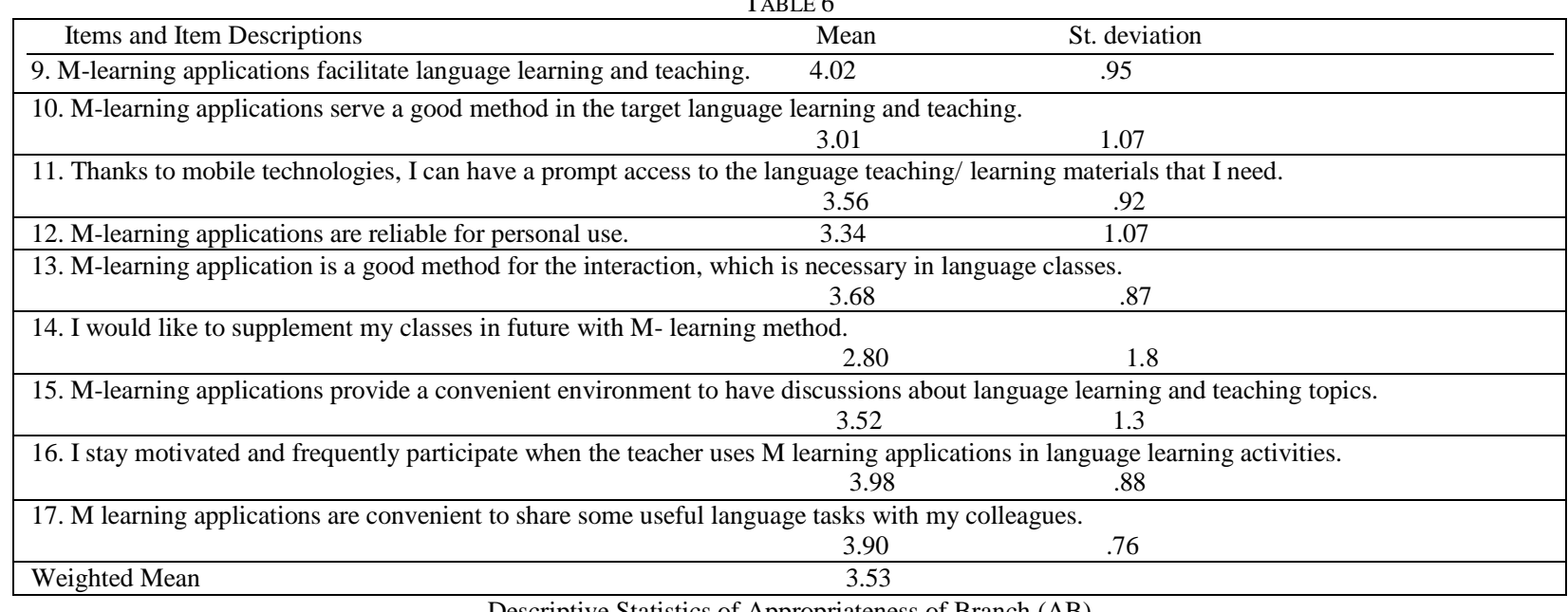

Descriptive Statistics of Appropriateness of Branch $(\mathrm{AB})$

The statistics of the given dimension are concerned with describing and exploring the appropriateness of MALL materials with reference to the learning's objectives (Zaminga et al., 2017). However, table (6) above indicates that the highest average score $(\mathrm{M}=4.02, \mathrm{SD}=.95)$ was ascribed to statement no.9 (M-learning applications facilitate language learning and teaching) while the lowest mean score $(\mathrm{M}=2.80, \mathrm{SD}=1.8$ ) was allocated to statement no.14 (I would like to supplement my classes in future with M- learning method). Furthermore, the total mean $(\mathrm{M}=3.53)$ for this indicator lies in the high-level interval [3.40 - 4.19] which suggests high appropriateness of MALL as a learning tool.

TABLE 7

\begin{tabular}{|lcc|}
\hline \multicolumn{1}{|c|}{ Items and Item Descriptions } & St. deviation \\
\hline 18. Language learning and teaching process should be supported with mobile-learning applications. & 3.79 & .84 \\
\hline 19. M-learning applications can be used to supplement the traditional education. & 4.00 & .95 \\
\hline 20. Mobile language learning applications can generate real-world, communicative tasks for language learners. & 3.85 & 1.17 \\
\hline & 3.60 & 1.03 \\
\hline 21. Teacher-student communication is facilitated by means of m-learning tools. & .97 \\
\hline 22. Communication is possible in chat programs by means of mobile technologies. 3.68 & .69 \\
\hline 23. Course materials can be sent to students via MMS. & 3.04 & .90 \\
\hline 24. Students and peers' communication is facilitated by means of M-learning tools. 3.63 & 3.54 \\
\hline 25. Learners can access the instructional websites with mobile technologies. & \\
\hline 26. Students can have more effective communication with mobile technologies than traditional methods. & 4.02 \\
\hline Weighted Mean & 3.68 \\
\hline
\end{tabular}


Similar to the previous dimensions, the purpose of this dimension is to investigate how M-learning works in the educational settings and evaluate its role in enhancing the learning process from the perspective of the learner (Zaminga et al., 2017). Based on table (7) above, MALL's apparatuses support and reinforce the educational process as it is inferred by the total average $(M=3.68)$. In addition, the highest mean score was assigned to the last statement $(M=4.02$, $\mathrm{SD}=1.3$ ) which is followed by the statement no. 19 (M-learning applications can be used to supplement the traditional education) with an average score $(\mathrm{M}=4.0, \mathrm{SD}=.95)$. The lowest mean $(\mathrm{M}=3.04, \mathrm{SD}=.69)$ score was allocated to statement no.23 (Course materials can be sent to students via MMS).

\section{B. Qualitative Analysis}

In addition to the M-Learning Perception Scale structured by Uzunboylu and Özdamlı (2011), an open-ended question was formulated to examine the advantages and disadvantages of using MALL as an educational instrument. A total of 58 learners responded to the question and justify their answers while the other participants did not provide any information. However, the given responses were revised, analyzed, and summarized by the researcher.

As the findings revealed, most of the responses were for the benefit of MALL. One of the learners (Hazem) stated that "I prefer MALL over the traditional method because it allows me to study at the time that I want". Others (Meznah, Amal, and Abdualrhman) emphasized the ability to effortlessly share the learning materials and aids such as the worksheets and lecture notes. Layla added, "as a translator, I use the mobile dictionary very often because I can easily find the words and terms". In addition, some students expressed their appreciation to the authentic material and content provided by MALL. One of the learners mentioned his experience in learning English via mobiles applications by saying "After 6 years in trying to learn English through the traditional methods, I learned English and how to speak English fluently after I used Cambly application. The application offers interesting content and good speaking activities".

Indeed, MALL in EFL classrooms suffers from a limited number of drawbacks. Some of the learners stated that using MALL as a learning apparatus may lead to various physical issues such as neck and back aches. Others admit that MALL prevents us as students to have more effective face-to-face interaction which is of important need. Manal clearly stated her resentment by saying "I admit the benefit of using technology in learning and teaching but I do not like its dominance, the role of the teacher becomes worthless which is a very bad result". Similarly, Ali affirmed that "Mobiles are expensive and not all students can afford them. Also, I support the traditional way of teaching since the required materials are affordable to all students".

\section{Research Main Findings}

The main findings of the present study can be summarized as follows:

1- Based on the result of Pearson Correlation, there is a strong and significant relationship between hours of using the mobile as a learning tool and the high GPA achievement. That is, the students who used mobiles and educational applications more often obtained a higher GPA than students who spent fewer hours on these applications.

2- The majority of the EFL learners expressed positive attitudes towards implementing and using mobiles in educational environments.

\section{DISCUSSION}

In the context of English language learning, the use of technology has proved a pivotal role in facilitating and enhancing the learning process. Therefore, and based on the present study's findings, the claim that using mobile would negatively affect the students' English proficiency is not supported by the evidence. As the analytical correlation revealed, there is a strong and significant relationship between the usage period of mobiles as an educational instrument and the achieved GPA by learners. Simply put, the students who used mobiles and educational applications more often obtained a higher GPA than students who spent fewer hours on these applications. Therefore, the present outcomes seem to be consistent with Hsu (2012), Rezaei et al., (2014) Loewen et al., (2019) findings.

The perceptions and attitudes of EFL learners have also been measured in the current investigation. A hybrid method (i.e., quantitative and qualitative) was applied to determine how EFL learners conceived MALL. An overwhelming majority of EFL learners assumed that MALL or m-learning has great potentials to effectively contribute to immersion classrooms. This can be attributed to the fact that mobile device "is becoming a mobigital virtual space where people can learn and teach digitally anywhere and anytime" (Şad \& Göktaş, 2013, p. 1). Furthermore, the qualitative and qualitative data revealed that the most positive attitudes were credited to the aptitude of m-learning in 1) assigning no time and place restrictions in learning, 2) providing lessons with good quality and various authentic materials, 3) increasing students' motivation, 4) facilitating communication and knowledge transmission, 5) assisting the learner in finding the information. This implies that the use of mobile and educational applications in learning English provides students with a more in-depth understanding of the subject being taught. Also, the data proposed high motivation and engagement of the students to learn and practice the language when mobiles are used. The reason could be credited to the authentic contents and activities that are provided by m-devices. It is also proved that the use of authentic materials such as videos and mobile games in presenting the educational content assist learners in processing the information 
(Rao, 2019). Therefore, the findings of the study approved the positive perception towards the use of MALL in EFL classrooms. Such a conclusion is corroborated by the work of Oz (2015) and Hsu (2013) and came against the studies of Dashtestani (2013) and Abidin et al (2016).

Furthermore, the qualitative data indicated some disagreements with M-learning. Some EFL learners admitted that fact that mobiles are not easily affordable, and not appropriate due to mobiles physical characteristics (i.e., small screen). This position is supported by previous studies such as Miangah and Nizarats' (2012) study. In addition, some students expressed their concerns about the use of mobiles in education as it may replace the role of the teacher. Such a misconception could impede the integration of technology in educational settings. It is crucial to understand the goal, nature, and limitations of technology when it is incorporated into education. Scholars such as Levy (2016) and Kassem (2018) emphasized balancing the use of technology to be not over or less used in the classroom. Others (Carlisle, 2014; Hedges; 2018) suggested using mobiles as a supplemental and secondary educational tool that is directed by the teacher and the lesson's objectives.

\section{CONCLUSION}

To sum up, the current study examined the effectiveness, usefulness, perceptions, and attitudes of integrating MALL into EFL classes. The findings of the study suggested a positive influence of MALL in educational settings and revealed high acceptance by the learners to employ such an approach in English classes. It also corroborates the fact that if mobile learning or MALL is employed systematically and thoroughly, it may improve the students' English proficiency since it provides more innovative and flexible learning methods. For the limitation of the study, the reader should bear in mind that this study was based on Saudi's universities, thus, the findings may not be completely generalizable to other contexts. Future researches should investigate the use of mobiles as a pedagogical tool in different educational contexts and settings. Also, the researcher may run an experimental study using t-test instead of correlation in order to examine the academic performance of two groups.

\section{REFERENCES}

[1] Abidin, Z., Mathrani, A., Parsons, D., \& Suriadi, S. (2016). Opportunities and challenges of mobile learning for promoting mathematical literacy. arXiv preprint, 16(06),02-09.

[2] Carlisle, K. (2014). Handheld technology as a supplemental tool for elementary general music education. General Music Today, 27(2), 12-17.

[3] Dashtestani, R. (2013). Implementing Mobile-Assisted Language Learning (MALL) in an EFL Context: Iranian EFL Teachers' Perspectives on Challenges and Affordances. Jalt CALL journal, 9(2), 149-168.

[4] El-Hussein, M. O. M., \& Cronje, J. C. (2010). Defining mobile learning in the higher education landscape. Journal of Educational Technology \& Society, 13(3), 12-21

[5] Froese, A. D., Carpenter, C. N., Inman, D. A., Schooley, J. R., Barnes, R. B., Brecht, P. W., \& Chacon, J. D. (2012). Effects of classroom cell phone use on expected and actual learning. College Student Journal, 46(2), 323-332.

[6] Geddes, S. J. (2004). Mobile learning in the 21 st century: benefit for learners. Knowledge Tree e-journal, 30(3), $214-228$.

[7] Godwin-Jones, R. (2017). Smartphones and language learning. Language Learning \& Technology, 21(2), 3-17.

[8] Hedges, S. H., Odom, S. L., Hume, K., \& Sam, A. (2018). Technology use as a support tool by secondary students with autism. Autism, 22(1), 70-79.

[9] Huang, Y. M., Lin, Y. T., \& Cheng, S. C. (2010). Effectiveness of a mobile plant learning system in a science curriculum in Taiwanese elementary education. Computers \& Education, 54(1), 47-58.

[10] Hsu, L. (2013). English as a foreign language learners' perception of mobile assisted language learning: a cross-national study. Computer assisted language learning, 26(3), 197-213.

[11] Kassem, M. A. M. (2018). Balancing Technology With Pedagogy In English Language Classroom: Teachers' perspective. International Journal of English Language Teaching, 6(9), 1-19.

[12] Kukulska-Hulme, A., \& Shield, L. (2008). An overview of mobile assisted language learning: From content delivery to supported collaboration and interaction. ReCALL, 20(3), 271-289.

[13] Kukulska-Hulme, A., \& Traxler, J. (Eds.). (2005). Mobile usability and user experience. Mobile learning: A handbook for educators and trainers, 21(3), 45-56.

[14] Kuznekoff, J. H., \& Titsworth, S. (2013). The impact of mobile phone usage on student learning. Communication Education, 62(3), 233-252.

[15] Kibona, L., \& Mgaya, G. (2015). Smartphones' effects on academic performance of higher learning students. Journal of Multidisciplinary Engineering Science and Technology, 2(4), 777-784.

[16] Larson-Hall, J. (2015). A guide to doing statistics in second language research using SPSS and R. UK: Routledge.

[17] Lee, M. J., \& Chan, A. (2007). Pervasive, lifestyle-integrated mobile learning for distance learners: an analysis and unexpected results from a podcasting study. Open Learning: The Journal of Open, Distance and e-Learning, 22(3), 201-218.

[18] Levy, M. (2006). Effective use of CALL technologies: Finding the right balance. Changing language education through CALL, $1(18), 301-320$.

[19] Loewen, S., Crowther, D., Isbell, D. R., Kim, K. M., Maloney, J., Miller, Z. F., \& Rawal, H. (2019). Mobile-assisted language learning: A Duolingo case study. ReCALL: the Journal of EUROCALL, 31(3), 293-311.

[20] Martin, F., \& Ertzberger, J. (2013). Here and now mobile learning: An experimental study on the use of mobile technology. Computers \& Education, 68, 76-85. 
[21] Metruk, R. (2020). Confronting the Challenges of MALL: Distraction, Cheating, and Teacher Readiness. International Journal of Emerging Technologies in Learning (iJET), 15(02), 4-14.

[22] Miangah, T. M., \& Nezarat, A. (2012). Mobile-assisted language learning. International Journal of Distributed and Parallel Systems, 3(1), 309-319

[23] Moore, M., \& Calvert, S. (2000). Brief report: Vocabulary acquisition for children with autism: Teacher or computer instruction. Journal of Autism and Developmental Disorders, 30, 359-362.

[24] O'Malley, C., Vavoula, G., Glew, J. P., Taylor, J., Sharples, M., Lefrere, P., \& Waycott, J. (2005). Guidelines for learning/teaching/tutoring in a mobile environment. England: Birmingham.

[25] Oz, H. (2015). An Investigation of Preservice English Teachers' Perceptions of Mobile Assisted Language Learning. English Language Teaching, 8(2), 22-34.

[26] Ozer, O., \& Kilıç, F. (2018). The effect of mobile-assisted language learning environment on EFL students' academic achievement, cognitive load and acceptance of mobile learning tools. EURASIA Journal of Mathematics, Science and Technology Education, 14(7), 2915-2928

[27] Pachler, N., Cook, J., \& Bachmair, B. (2010). Appropriation of mobile cultural resources for learning. International Journal of Mobile and Blended Learning (IJMBL), 2(1), 1-21.

[28] Petkov, M., \& Rogers, G. E. (2011). Using Gaming to Motivate Today's Technology-Dependent Students. Journal of STEM Teacher Education, 48(1), 7-12.

[29] Plonsky, L., \& Oswald, F. L. (2014). How big is "big"? Interpreting effect sizes in L2 research. Language Learning, 64(4), 878-912.

[30] Pollara, P., \& Kee Broussard, K. (2011). Student perceptions of mobile learning: A review of current research. In Proceedings of Society for Information Technology \& Teacher Education International Conference 2011 (pp. 1643-1650).

[31] Rao, P. S. (2019). The Effective Use of Authentic Materials in the English Language Classrooms. Humanities, 7(1), 1-8.

[32] Rezaei, A., Neo, M. \& Pesaranghader, A. (2014). The Effect of Mobile Applications on English Vocabulary Acquisition. Journal Technology, 87(32), 100-115.

[33] Robson, C. (2011). Real World Research. Oxford. UK: Blackwell Publishers.

[34] Rost, M. (2002). Teaching and Researching Listening. London, UK: Longman.

[35] Sabzian, F., \& Gilakjani, A. P. (2013). Teachers' attitudes about computer technology training, professional development, integration, experience, anxiety, and literacy in English language teaching and learning. International Journal of Applied Science and Technology, 3(1), 67-75.

[36] Şad, S. N., \& Göktaş, O. (2013). Preservice teachers' perceptions about using mobile phones and laptops in education as mobile learning tools. British Journal of Educational Technology, 45, 606-618.

[37] Saidouni, K., \& Bahloul, A. (2016). Teachers and students' attitudes towards using mobile-assisted language learning in higher education. Arab World English Journal (AWEJ) Special Issue on CALL, (3), 76-84.

[38] Saran, M., Seferoğlu, G., \& Çağıltay, K. (2009). Mobile assisted language learning: English pronunciation at learners' fingertips. Eurasian Journal of Educational Research, 34, 97-114.

[39] Sung, Y. T., Chang, K. E., \& Liu, T. C. (2016). The effects of integrating mobile devices with teaching and learning on students' learning performance: A meta-analysis and research synthesis. Computers \& Education, 94, 252-275.

[40] Uzunboylu, H., \& Özdaml1, F. (2011). Teacher perception for m-learning: Scale development and teachers' perceptions. Journal of Computer Assisted Learning, 27(6), 544-556.

[41] Viberg, O., \& Grönlund, ̊. (2013). Cross-cultural analysis of users' attitudes toward the use of mobile devices in second and foreign language learning in higher education: A case from Sweden and China. Computers \& Education, 69, 169-180.

[42] Wu, W., Wu, Y. J., Chen, C., Kao, H., Lin, C., \& Huang, S. (2012). Review of trends from mobile learning studies: A metaanalysis. Computers \& Education, 59(2), 817-827.

[43] Zaki, A. A., \& Yunus, M. M. (2015). Potential of Mobile Learning in Teaching of ESL Academic Writing. English Language Teaching, 8(6), 11-19.

[44] Zaminga, S., Guidetti, G., Badagliacca, R., Sottimano, I., Viotti, S., \& Converso, D. (2017). Mobile learning perception scale: A short version for the Italian context. Psychology, 23(5).

Raghad Y. Alkhudair is an MA student in theoretical linguistics program at Qassim University, Saudi Arabia. She received a bachelor's degree in English language and translation with an excellence and first honor degree. 